\title{
Frames and the Interpretation of Omitted Arguments in English
}

Josef Ruppenhofer and Laura A. Michaelis

\section{Hildesheim University and University of Colorado}

Despite the idiosyncratic properties of null-complement phenomena observed by Fillmore (1986), Lambrecht and Lemoine (2005), and others, many researchers have pursued large-scope, single-factor explanations of the distributional and interpretive restrictions on null complements - in particular, explanations based on Aktionsart (Rappaport Hovav and Levin 1998) and selectional restrictions (Resnik 1993, 1996). We argue instead for a limited implicational regularity tying the interpretation type of an omitted argument to the frame membership of its predicator. We show that our account is robust, that exceptions can be explained based on independently motivated principles, and that the proposed generalization can be motivated by reference to the discourse status of comparable overt arguments in both lexically and constructionally licensed omissions. Finally, we argue that successful generalizations in the realm of null complementation are likely to be narrow rather than broad in scope.

\section{Introduction}

The meaning of a predicator generally determines its combinatoric potential. For example, the verb contribute selects the syntactic dependents that it does (NP, NP, PP) because it denotes a transfer event that involves the three corresponding semantic dependents - agent, theme and recipient, as in, e.g., She contributed $\$ 100$ to the campaign. Speakers are not always maximally explicit, however, and (1-3) are equally valid alternatives:

(1) She contributed to the campaign.

(2) She contributed $\$ 100$.

(3) She contributed.

The interpreter of (1) is required to recover a theme argument, that of (2) a recipient argument, and that of (3) both a recipient and theme argument. While such examples might appear to illustrate a general effort-conservation strategy of omission up to 
recoverability, not all predicates display the same degree of flexibility. The apparently parallel transfer verb convey is a case in point:

(4) *International aid teams conveyed to Burma.

(5) International aid teams conveyed supplies.

(6) *International aid teams conveyed.

When precisely do speakers leave semantic roles unspoken and how do these constraints aid the interpreter in recovering those missing roles? Since Fillmore's seminal (1986) work on lexically licensed null complements in English, scholars have turned increasingly toward single-factor explanations, in particular, recoverability of the referent of the unexpressed argument (Resnik 1993, 1996; Goldberg 2005, 2006) and Aktionsart of the licensing verb (Rappaport Hovav and Levin 1998; Wright and Levin 2000). These explanations are undermined, however, by the very idiosyncrasies that Fillmore emphasized: lexical differences (nearly synonymous predicators like eat and devour differentially allow omission of the theme argument), interpretive differences (e.g., $I$ know ø has an anaphoric null argument, while I was eating ø has an existential one) and effects of constructional context (e.g., verbs that disallow null complements when interpreted episodically allow them in generic/habitual contexts, as in She impresses ø every time). In addition, as Ruppenhofer and Michaelis (2010) observe, otherwise prohibited definite null complements are licensed in certain genres, e.g., labelese, diary style, match reports and recipe imperatives. Examples include the match-report and labelese predications in (7-8), respectively:

(7) Juice Williams keeps [the ball]. (College football, ESPN, 11/1/08)

(8) Massage [this lotion] onto wet or dry skin in gentle, circular motions. 
(foot scrub lotion label)

That null-complementation potential in English is regulated by particular constructions and lexemes, rather than context more generally, is particularly evident when one notes the relative freedom with which, e.g., definite null complements are employed in French. As Lambrecht and Lemoine argue (2005:40), a topically construed null argument in French represents a default solution in cases like (9):

(9) [Tasting a wine] J'aime/\#J'aime ça/\#Je l'aime. 'I like [it].'

As Lambrecht and Lemoine argue, the use of a null complement in this context allows the speaker to avoid unwanted implications associated with either of the two overt argumentencoding options shown: the pronoun ça has a generic reading (the speaker generally likes this type of wine), and the pronoun le has an animate reading (the speaker likes a particular person). The English verb like displays no such flexibility, as shown by the ungrammaticality of (10):

(10) *I like [it].

It appears then that null-complementation affordances in English are not 'emergent' from discourse; rather, they are licensed by an array of lexemes and constructions (including those indexed to genres). The nonuniformity of null complementation phenomena in English suggests that gaining predictive power in this domain requires a suite of narrow-scope generalizations. Using data from the British National Corpus (BNC), we suggest such a generalization, based on the frame-semantic categories of null complement-licensing predicators: if two or more verbs belong to the 
same FrameNet frame (in terms of Ruppenhofer et al. 2006) and license the omission of a particular frame element (FE), the interpretation type of the omitted FE is the same for all such predicators. ${ }^{1}$ For example, among the lexical units in the Arriving frame (e.g., approach, arrive, come, enter, return), some allow omission of the Goal FE under an anaphoric interpretation (11), while others (e.g. reach, get) do not (12). ${ }^{2}$ No lexical unit in the Arriving frame, however, allows omission of the Goal under an existential interpretation (in which the identity of the goal need not be known to the speaker), as in (13):

(11) We arrived (in Sydney) at eight in the morning.

(12) Our last stop before we reached *(Sydney) was Canberra.

(13) \#A: Bill just told me he arrived. B: Oh where? A: I don't know. Just somewhere.

We demonstrate both the robustness of this implicational regularity and the motivated nature of exceptions to it, arguing that it provides a better account of the data than competing explanations. This paper is structured as follows. In section 2 , we introduce a taxonomy of omissions that will enable us to delimit the set of facts that we intend to account for. In section 3, we provide evidence for our central claim - that the construal type of a null complement is predicted by the frame membership of the predicator that

\footnotetext{
${ }^{1}$ All labels used in this paper to refer to frames, lexical units of frames and frame elements of frames are taken from the online FrameNet database (https://framenet.icsi.berkeley.edu/fndrupal/index.php?q=frameIndex).

2 The omissibility contrast for the Goal arguments of arrive and reach might appear attributable to the grammatical functions of the unexpressed arguments: English does not generally allow definite (as opposed to indefinite) null complements that represent direct objects (as opposed to clauses and preposition phrases). However, the following examples show that this is not a hard constraint:

a. They approached (me) slowly.

b. Could I see (it)?

c. Give me (that)!

d. I won (the race).
} 
licenses that complement. In section 4, we compare our account to previous analyses, focusing on explanations based on lexical aspect and selectional restrictions. In section 5, we discuss a potential motivation for the frame-based generalization based on the discourse status of overt arguments of predicators that also allow these same arguments to be unexpressed. In section 6 , we discuss why valid generalizations about null instantiation are likely to be as narrow in scope as the one that we offer. We offer concluding remarks in section 7.

\section{A Taxonomy of Omissions}

Omissions of core arguments of predicates are categorized along two dimensions: the identity of the licensor and the interpretation that the unrealized argument receives. Licensor classification is based on the observation that either a particular predicator or a particular grammatical construction must be present in order for the omission of a frame element to occur. For instance, in (14), the omission of the agent is licensed by the passive construction:

(14) No doubt, mistakes were made $\varnothing$.

The omission in (14) is viewed as a constructional one, because any verb that combines with the passive construction allows it. By contrast, the omission in (15) is lexically specific: the verb arrive allows the Goal to be unspecified whereas the verb reach, also a member of the Arriving frame, does not, as seen in (12) above.

$$
\text { (15) We arrived [ } \varnothing^{\text {Goal] }} \text { at } 8 \text { pm }
$$

These two examples also illustrate the second major dimension of variation: the interpretation of the omitted argument. In the case of the passive construction illustrated 
in (14), the participant making the mistake need not be mutually known to the interlocutors - that is, the omission is an instance of indefinite null instantiation (INI). By contrast, the Goal location of arrived in (15) is an entity that must be accessible to speaker and hearer from the linguistic or physical discourse context — that is, the omission is an instance of definite null instantiation (DNI).

It is important to observe that a predication with an indefinite null complement can be used even in a context where the missing frame element has a relatively specific interpretation, as in the following passage retrieved from Google: my dog got access to dog food and ate until his stomach look[ed] like a basketball. In this passage, the ediblesubstance argument of eat is construed as dog food, rather than edible material in general. Insofar as this is the case, the missing argument of ate could be reconstructed as the bare nominal dog food or even the definite NP the dog food. Further, this instance of INI does not pass the 'admission of ignorance' diagnostic proposed by Fillmore (1986: 96): the writer of the above passage could not plausibly go on to admit: "I don't know what the dog ate". These facts in turn suggest that INI is like overt indefinite reference, as Gundel et al. 1993 describe it. The Givenness Hierarchy proposed by Gundel et al. is implicational; the conditions which welcome a particular referring form also license the use of any lower ranked form: "each status entails (and is therefore included by) all lower statuses, but not vice versa" (Gundel et al. 1993:276). Thus, an indefinite NP can be used to implicate (via Grice's second maxim of quantity) a greater degree of cognitive salience of the denoted referent than that which licenses the use of an indefinite NP. An example is found in the following passage retrieved from Google: [...] a trans man wrote an article saying virtually the same thing and it got noticed. [...] Why? Because a man said 
$i t$. In this instance, the indefinite NP a man refers to a discourse-active ('in focus') entity rather than to a discourse-new entity (the trans man mentioned earlier); it is thus replaceable by the pronoun $h e$. But there is a critical difference between overt indefinite reference and INI: indefinite unexpressed arguments are resistant to anaphoric construal and are thus not replaceable by pronominal arguments. Notice, for example, that the zero argument in the above passage is not readily replaced by a definite pronominal argument: my dog got access to dog food and ate some/??it until his stomach look[ed]like a basketball. In other words, while the givenness status of an INI instance can often be contextually enriched up to what Gundel et al. 1993 refer to as 'uniquely identifiable' status, INI instances appear to be upper-bounded at this status. This is a point made famously by Fillmore, using another canine example (1986:97):

The indefinite null complement can be seen to have much in common with a syntactically present indefinite noun phrase: it is markedly indefinite, by which I mean obligatorily disjoint in reference with anything saliently present in the discourse context. Adrian Akmajian, in conversation, once illustrated this point by describing a situation in which one person said WHAT HAPPENED TO MY SANDWICH?, and another said FIDO ATE. This cannot be a well-formed conversation.

In light of the foregoing considerations, we will diagnose an unexpressed argument as INI if it is replaceable by an indefinite expression (e.g., something, someone) and not replaceable by an anaphoric pronoun (e.g., it, him), even if (a) the predication missing that argument does not pass the 'admission of ignorance' diagnostic and (b) the missing argument could be reconstructed as a definite NP. 
Of the four possible combinations of licensor and interpretation, the current study targets only lexically licensed omissions. For more discussion of the properties of various constructionally licensed omissions, we refer the reader to Ruppenhofer (2004) and Goldberg (2006). For discussion of how null complementation may be represented, we refer the reader to Ruppenhofer and Michaelis (2010) for a Construction Grammar treatment and to Gillon (2012) for a model-theoretic approach.

\subsection{Complications}

There are two kinds of cases that present problems for the taxonomy outlined above. In the first class of cases, it is hard to decide whether to call an omitted FE an instance of DNI or of INI. In the second class of cases, the absence of an FE is more appropriately treated as licensed by a macro-role relationship, or by a frame-internal construal alternation, than as an instance of null complementation.

\subsubsection{Difficulties Identifying the Interpretation Type}

Consider the Body MOVEMENT frame, which is concerned with events of animate beings' moving body parts. As exemplified in (16) and (17) by the verb pout, many verbs in this frame can occur without overt mention of the body part:

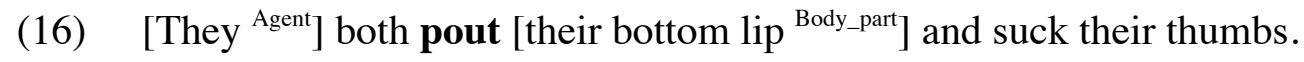

(17) Her only top-three finish at the worlds was a silver last year, when [she $\left.{ }^{\text {Agent}}\right]$ pouted $\left[\varnothing^{\text {Body_part }}\right]$ and took the medal off her neck on the podium.

On the one hand, we could call these omissions DNI, since we can identify a specific individual as the possessor of the relevant body part. On the other hand, these omissions 
can, and typically do, occur in contexts where the body part has never been mentioned, suggesting that these cases are actually like those of She smokes, I ate at noon, etc., in which interpreters can resolve the unrealized argument to a specific referent based merely on world knowledge.

Another frame displaying similar characteristics is the CONDUCT frame. The verb behave may occur either with an overt Manner specification, as in (18), or without one, as in (19):

(18) “Just behave [as if we were back at home Manner]," said Hazel.

(19) Now apologize and behave [ $\left.\varnothing^{\text {Manner }}\right]$, or go and ride with your mother.

(Despite its name, which implies adjunct status, Manner is a core frame element in this frame.) Tokens of behave, as in (19), must be interpreted as meaning 'behave well.' While we know the particular value of the Manner specification, it need not be mentioned at all in the discourse. Such examples thus again raise the question of whether to call the omitted frame element a case of DNI or a case of INI. For our purposes, it is unimportant which view we take of cases like Bodypart in the BODY MOVEMENT frame and Manner in the CONDUCT frame, as long as we take a consistent view for all lexical units within a given frame.

\subsubsection{Non-instantiation}

In this section we draw a distinction between non-instantiations and null-instantiations, excluding the former from our purview. We consider two subcases of noninstantiatiation: (a) two alternative construals exist within the same frame; and (b) several 
frame elements belong to a single macro-role. An example of a frame that contains two alternative construals is the Separating frame. ${ }^{3}$

One construal associated with this frame is the break-up construal exemplified by (20), which involves a whole and a set of subparts created from that whole. The second construal is the splitting-off construal, exemplified in (21). It includes a source argument (Part 2) and a theme argument that moves away from Part 2 (Part 1).

(20) Break up: [The field of twelve teams ${ }^{\text {Whole }}$ ] was split [into four groups of three ${ }^{\text {Parts }}$ ]

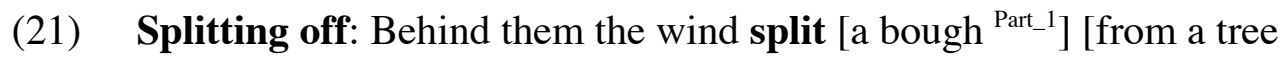
${ }^{\text {Part_2}}$ ] with a sharp crack.

When one construal is chosen over the other, it is not meaningful to say that the FEs associated with the other construal are missing. That is, it would be inappropriate to analyze (20) as involving null instantiation of Part 1 and Part 2. Likewise, (21) does not exemplify null instantiation of the Whole frame element. This is not to say that these two construals do not allow null instantiation of their arguments. For example, when the break-up construal is chosen, one can find instances of indefinite null instantiation of the Parts frame element, as in (22):

(22) $\left[\right.$ Palestine $\left.{ }^{\text {Whole }}\right]$ has been partitioned a number of times.

A second, similar case consists of frames in which all FEs from a set of several compatible FEs can be instantiated, but only one must be instantiated. FrameNet refers to such constellations of frame elements as coresets. The case of coresets is similar to that of obligatory adjuncts, as described by Goldberg and Ackerman (2001): an additional

\footnotetext{
3 Arguably, the two construals could also be analyzed as distinct frames. We will, however, rely on the current frame organization of FrameNet.
} 
specification is needed to make a predication felicitous in context, but the content of that specification is not constrained. An example of a coreset is provided by the VERDICT frame: in the VERDICT frame, either the Charges (23), the Case (24) or both (25) can be expressed.

(23) [The two Koreans firms $\left.{ }^{\text {Defendant }}\right]$ have been cited for alleged dumping each year since 1993 but each time have been cleared [of the charge Charges].

(24) Also Tuesday, Hamas leaders stepped up their criticism of [the Palestinian Authority, which ${ }^{\text {Judge }}$ ] cleared [Israel ${ }^{\text {Defendant] }}$ [in the March 29 killing of the group's chief bombmaker $\left.{ }^{\text {Case }}\right]$.

(25) [A jury $\left.{ }^{\text {Judge }}\right]$ acquitted [him $\left.{ }^{\text {Defendant }}\right]$ [of attempted murder and aggravated assault ${ }^{\text {Charges }}$ [in the shootout case ${ }^{\text {Case }}$ ].

When neither of these FEs is instantiated, one still has to be able to infer either one or both of them. Example (26) requires a DNI construal, but it is not clear which of the two metonymically related frame elements is 'really' missing.

(26) [Palestinian Authority officials $\left.{ }^{\text {Judge }}\right]$ unequivocally cleared [Israel Defendant].

Context may, but need not necessarily, point to a particular FE as the missing one, if both FEs have been mentioned before. For our purposes, the non-instantiation of a specific subtype FE of a macro FE is not important; we will be interested only in whether the macro FE is instantiated. 


\section{Predicting the Interpretation Type of a Null Complement}

We now turn to our main concern: predicting the interpretation of a lexically licensed null argument. We stress that we are not trying to predict the null-complementation affordance itself. In other words, we will not give an account of why arrive allows the omission of its Goal FE but reach does not. In our view, this prediction cannot be accurately made. Neither do we consider it possible to predict which of a lexical unit's arguments is omissible based on the morphosyntax, grammatical function, or coarsegrained semantic role of the argument. We deliberately restrict our account to the interpretation type of arguments that we know to be omissible. That is, we explain why, when the Goal of arrive is omitted, it is interpreted as a DNI rather than an INI. The reasons why we consider the other two prediction tasks to be infeasible will be discussed in section 6 .

\subsection{The Framal Implicational Account}

As defined by Fillmore $(1982,1985)$, Frame semantics is a semantics of understanding. It assumes that lexical units are organized in the mental lexicon according to which scenarios or schematic experiences they are used to talk about. Rather than being concerned with meanings consisting of atomic features such as [+human] or [+slow], the unit of analysis are abstract holistic experiences. Individual lexical items are taken to refer to particular participants or to impose a particular profile on the relations within the larger scenario.

To illustrate, consider the REVENGE frame, which we can define as follows:

An Agent performs a Response action on an Offender as a punishment for an earlier 
action, the Injury that was inflicted on an Injured party. The Agent need not be identical to the Injured party but needs to consider the Offender's prior action a wrong. Importantly, the punishment of the Offender by the Agent is seen as justified by individual or group opinion, rather than by law.

The words and multi-word expressions that evoke the REVENGE frame include avenge, avenger, get back (at), get even (with), payback, retaliate, retaliation, retribution, retributive, retributory, revenge, revengeful, revenger, sanction, vengeance, vengeful, and vindictive. Some of these lexical units are exemplified in (27)-(29):

(27) [Deep River $\left.{ }^{\text {Avenger }}\right]$ avenged [an earlier round-robin loss to the Petawawa Pepsis ${ }^{\text {Injury }}$ ] [by defeating them 4-0 to win the A final game ${ }^{\text {Response action }}$.

(28) Among the conventions of the genre, the ghost of the person to be avenged appears to spur on [[his $\left.{ }^{\text {Injured party }}\right]$ revenger $\left.{ }^{\text {Avenger }}\right]$.

(29) Syria has warned the United States of retaliatory [measures ${ }^{\text {Response action] }}$ if Washington launches another incursion into the country's territories. The words illustrated profile different parts of the overall REVENGE frame: the verb in (27) refers to the overall scenario; the noun in (28) denotes the Agent frame element; and the adjective in (29) modifies the Response action. All these lexical units are interpreted within a conceptual framework in which one remedies a perceived injury through the performance of an action viewed as recompense.

Let us now consider some of the roles that can be omitted by the verbs in the Revenge frame. As example (30) shows, the FE Injury, denoting the prior action that is to be punished, can be omitted. This same example also illustrates that the Response action FE may be missing. 
John intended to avenge himself on/get back at/get even with/retaliate against/take revenge on Sue $\left[\varnothing^{\text {Injury }}\right]\left[\varnothing^{\text {Response action }}\right]$.

Note that the interpretation type of the unexpressed Injury FE is different from that of the unexpressed Response action. While the former is a case of DNI, the latter is a case of INI. As evidence for this claim, consider that while (31) appears to be a contradiction, (32) does not:

(31) ? John finally got even with Sue, but I don't know what for.

(32) John finally got even with Sue, but I don't know in what way.

More important, the interpretation of both kinds of missing FEs is the same for all the verbal predicators illustrated in (30), and in fact for all verbal predicators in the frame. That is, there is no verbal predicate that can omit the Injury FE under an INI interpretation and none that can omit the Response action FE under a DNI interpretation. In fact, we claim here that the regularity concerning the interpretation types of the Injury and Response action FEs in the REVENGE frame is but one instance of a more general regularity, which we state in (33):

(33) If a particular frame element role is lexically omissible under a particular interpretation (either anaphoric or existential) for one LU in a frame, then for any other LUs in the same frame that allow the omission of this same FE, the interpretation of the missing FE is the same.

Let us consider the scope of this implicational characterization. First, the implication applies separately to each individual FE of a particular frame. Thus, there is no contradiction in the fact that the Injury FE can be omitted under a DNI interpretation and the Response action under an INI interpretation. Equally important is the fact that 
frame elements are frame specific. Thus, if a frame other than REVENGE also had a FE named Injury, the two frames would have to be treated as distinct. Should the Injury FE in that other frame also be omissible, then we could not, and would not have to, make a prediction about its interpretation type based on the properties of the REVENGE frame. Finally, the implication does not require that an FE that can be omitted by any verbal predicate in a frame can likewise be omitted by all the other verbal predicates in the frame. Accordingly, (33) captures the behavior of verbs within the Arriving frame-in particular the fact that, as shown in examples (11) - (12) above, arrive can omit the Goal FE but verbs like reach cannot.

In order to determine whether a verb's frame membership predicts the interpretation type of its null complement(s), one must examine each FrameNet frame and each frame member, controlling for the particular frame element that is unrealized. An annotation effort currently being conducted by the two authors of this paper will determine conclusively whether the implicational generalization in (33) holds. In this ongoing annotation effort, which, like the present study, uses data from the British National Corpus, the authors are labeling sets of sentence tokens that exemplify each of the top 20 FrameNet frames, whereby 'top' we mean those frames with the highest rate of null instantiation, as measured by the number of verbal lexical units within each frame that permit null instantiation of at least one FE. From each of these 20 frames, we have retrieved data up to 10 verbal lexical units subsumed by that frame. For each of these ten verbs in each of the 20 frames, we have used automated methods to retrieve all sentential tokens of that verb in which a specific, target FE is unexpressed. For each such instance, we are tagging the interpretation type (INI or DNI) of that missing FE. The goal is to 
determine whether the selected FE consistently receives a DNI or INI construal across all tokens of a given verb and all verbal lexical units within each frame. If the answer is yes, in the main, we will have upheld our implicational generalization. ${ }^{4}$

While statistical results of the annotation effort described above are not yet available, we can at this point report the results of a pilot study that appears to confirm the generalization in (33). For the pilot, we randomly selected 14 frames from the FrameNet frame index; these are listed in Table 1 below. We ensured that each of the 14 frames selected satisfied the following constraint: the frame must contain more than one verbal LU that has more than one core FE, and at least one of those core FEs must be capable of null expression. When a frame had more than one FE subject to null instantiation, we randomly selected an FE to analyze. For each of the 14 frames, we selected (at most) five of the verbal LUs associated with that frame in the FrameNet frame index. Using BNC data, we labeled up to 20 sentential tokens of each verb in which the target FE was covert. A token was labeled 'DNI' if, in the context, the missing FE could be reconstructed by means of pronominal or definite NP and 'INI' if the missing FE was more appropriately reconstructed as an indefinite NP (a bare mass or plural noun or a NP containing an indefinite determiner like some). The examples (34) (39), to be discussed below, give illustrations of both DNI and INI 'reconstructions' (shown in square brackets).

Table 1 lists the 14 frames that were checked (column one), the relevant FE in the frame (column two), the interpretation type of that FE (column three) and an example of

\footnotetext{
${ }^{4}$ In a parallel effort, we are annotating the givenness status of overt mentions of the target FE in each of the selected frames, using the same set of verbal LUs used for the study of covert mentions. This analysis will enable us to determine whether trends in the givenness status of an overt FE, as indicated by the morphosyntactic coding of overt mentions, are consonant with the construal pattern for that FE when covert. See section 5 for a discussion of expected trends in this area.
} 
the predominant usage pattern (column 4). In each case, we confirmed that the relevant FE, when null instantiated, has the same interpretation (indefinite or definite) across each verbal lexical unit in that frame.

A couple of examples will suffice to demonstrate the validity of the implicational generalization in (33). The first example involves the Quitting frame. As indicated in the eleventh row of Table 1, verbs in the Quitting frame impose a DNI construal on an uninstantiated Employer argument. This pattern is illustrated shown in (34) - (36), respectively, for three verbal lexical units from this frame: resign, abdicate and quit:

(34) The president of the Banco Central, Javier González Fraga, resigned [the presidency of the bank] on Nov. 23, 1989, and was replaced by Egídio Iannella.

(35) Edward was next in line but he abdicated [the British throne] for Mrs. Simpson.

(36) John Major is slightly more likely to keep his job than England football manager Graham Taylor but both are odds-on to quit [their jobs].

The second example involves the Filling frame. As shown in the eighth row of Table 1, Filling verbs impose an INI construal on an unexpressed Theme argument. This pattern is illustrated in (37 - 39), respectively, for three verbal lexical units from this frame: load, fill and coat:

(37) They loaded the car [with things] and then Fosdyke offered to take the children for a coke in the café opposite the petrol pumps.

(38) But for the woman who travels the world filling her massive shopping basket [with foodstuffs], stocking her own fridge is a much less detailed 
affair

(39) Should I coat the brickwork and mortar [with something] to make them waterproof? 


\begin{tabular}{|c|c|c|c|c|}
\hline Frame & FE & Verbal LUs & Type & Example \\
\hline Activity resume & Activity & $\begin{array}{l}\text { renew, restart, } \\
\text { resume }\end{array}$ & DNI & $\begin{array}{l}\text { We RESUMED an } \\
\text { hour later }\end{array}$ \\
\hline Amalgamation & Whole & $\begin{array}{l}\text { amalgamate, } \\
\text { blend, combine, } \\
\text { fuse, meld }\end{array}$ & INI & $\begin{array}{l}\text { Simmer until the } \\
\text { flavours have } \\
\text { BLENDED. }\end{array}$ \\
\hline Bearing arms & Weapon & $\begin{array}{l}\text { be armed, } \\
\text { draw, carry, } \\
\text { pack }\end{array}$ & INI & $\begin{array}{l}\text { Careful, that guy } \\
\text { CARRIES. }\end{array}$ \\
\hline $\begin{array}{l}\text { Becoming a } \\
\text { member }\end{array}$ & Group & $\begin{array}{l}\text { enlist, enroll, } \\
\text { enter, join, sign } \\
\text { up }\end{array}$ & DNI & $\begin{array}{l}\text { That summer he } \\
\text { ENLISTED as an } \\
\text { air-raid warden. }\end{array}$ \\
\hline Body movement & Body part & $\begin{array}{l}\text { blink, clap, } \\
\text { nod, shrug, } \\
\text { wave }\end{array}$ & $\begin{array}{l}\text { DNI, } \\
\text { INI }\end{array}$ & $\begin{array}{l}\text { Owen WAVED to } \\
\text { him urgently. }\end{array}$ \\
\hline Bungling & Action & $\begin{array}{l}\text { blow, botch, } \\
\text { mess up, screw } \\
\text { up }\end{array}$ & DNI & $\begin{array}{l}\text { I SCREWED UP big } \\
\text { time. }\end{array}$ \\
\hline Exclude member & Group & $\begin{array}{l}\text { exclude, } \\
\text { excommunicate } \\
\text { expel }\end{array}$ & DNI & $\begin{array}{l}\text { Please, some bishop, } \\
\text { any Bishop, } \\
\text { EXCOMMUNICATE } \\
\text { her. }\end{array}$ \\
\hline
\end{tabular}




\begin{tabular}{|c|c|c|c|c|}
\hline Filling & Theme & $\begin{array}{l}\text { adorn, coat, } \\
\text { daub, fill, load, }\end{array}$ & INI & $\begin{array}{l}\text { I sat there for an } \\
\text { hour STUFFING my } \\
\text { stomach. }\end{array}$ \\
\hline Grasp & Phenomenon & $\begin{array}{l}\text { comprehend, } \\
\text { get, grasp, see, } \\
\text { understand }\end{array}$ & DNI & $\begin{array}{l}\text { You 'll } \\
\text { UNDERSTAND } \\
\text { when you get a little } \\
\text { older. }\end{array}$ \\
\hline Institutionalization & Facility & $\begin{array}{l}\text { commit, } \\
\text { hospitalize, } \\
\text { institutionalize }\end{array}$ & INI & $\begin{array}{l}\text { We had to } \\
\text { HOSPITALIZE him. }\end{array}$ \\
\hline Quitting & Employer & $\begin{array}{l}\text { abdicate, leave, } \\
\text { quit, resign, } \\
\text { step down }\end{array}$ & DNI & I QUIT! \\
\hline $\begin{array}{l}\text { Remembering to } \\
\text { do }\end{array}$ & Action & $\begin{array}{l}\text { forget, } \\
\text { remember }\end{array}$ & DNI & $\begin{array}{l}\text { I'd quite } \\
\text { FORGOTTEN till } \\
\text { now. }\end{array}$ \\
\hline Request & Addressee & $\begin{array}{l}\text { ask, beg, } \\
\text { implore, } \\
\text { entreat, } \\
\text { demand }\end{array}$ & DNI & $\begin{array}{l}\text { The offenders } \\
\text { DEMANDED } \\
\text { money. }\end{array}$ \\
\hline Separating & Parts & $\begin{array}{l}\text { divide, part, } \\
\text { partition, } \\
\text { separate split }\end{array}$ & INI & $\begin{array}{l}\text { Let's DIVIDE the } \\
\text { loot later. }\end{array}$ \\
\hline
\end{tabular}


Table 1: Frames examined

\subsection{Accounting for Exceptions}

Like many linguistic regularities, the framal regularity concerning the interpretation type of omitted FEs has some exceptions. Analysis of these exceptional cases, however, shows that these exceptions are motivated ones, in addition to being relatively rare.

Consider, for example, the contrast between the verbs resign and retire, as they pertain to employment or the occupation of an official role. Both are members of the Quitting frame and as such designate a situation in which a person, the Employee, gives up her work relation with a particular company or institution, the Employer. While a felicitous use of resign with a null-instantiated Employer FE requires that the referent be recoverable from context (40), this condition is not true for retire (41):

(40) $\left[\mathrm{Mr}\right.$ Spitzer $\left.{ }^{\text {Employee }}\right]$ resigned $\left[\varnothing^{\text {Employer }}\right]$ today amid the scandal over a \$US1000-an-hour (\$1070) prostitute.

(41) My mom is not looking forward to the fact that [my dad $\left.{ }^{\text {Employee }}\right]$ is going to retire soon.

We account for the exceptional behavior of retire by proposing that it, unlike other lexical units in the Quitting frame, entails that the Employee has undergone a permanent status change: s/he is no longer in the labor market. Crucially, we note, this focus on the current status of a participant (rather than on the precipitating event) also motivates the pattern of omission illustrated in (42):

(42) [This lion ${ }^{\text {Killer }] ~ h a s ~ k i l l e d ~ b e f o r e . ~}$ 
The omission in (42) appears to be a constructionally licensed one: the licensor is the existential perfect construction (Goldberg 2005): by having killed, the lion has acquired the status of being a dangerous animal. Thus, the resultant-state entailment, whether attached to a lexeme or a construction, overrides the interpretive bias imposed by membership in a particular FrameNet frame.

Exceptions of this same type are also found within the Personal Relationship frame. This frame contains LUs that denote people in relationships (e.g., friend), the relationships themselves (friendship) and events of starting or ending relationships (e.g., befriend). The predicates and nouns in this frame are normally used in contexts where a specific pair of individuals is accessible in discourse. In (43), the mother in question is the mother of a discourse-accessible playmate of the speaker's son. In (44), the miniature pinscher's relative in question is the Doberman pinscher.

(43) And, as I got to know the mother [ $\left.\varnothing^{\text {Relative }}\right]$ better, I realized we had little in common.

(44) The miniature pinscher originated in Germany several centuries ago, and even though he looks like a small Doberman pinscher, he is not related $\left[\emptyset^{\text {Relative }}\right]$.

Clearly, it is not informative to assert that someone or something is related without specifying a relative. All individuals and species have relatives. However, some relational nouns, like mother or father, are sufficiently informative to be usable without specification of the relative. Consider example (45), where the second relative, $\mathrm{Mr}$. Smith's child, need not have been mentioned before at all.

(45) Mulder offered himself as a hostage in exchange for Mr. Smith, who had 
just become a father $\left[\varnothing^{\text {Relative }}\right]$ for the first time.

The complement of father can be omitted in (45), because being a father itself is a status that has significance: the person has responsibilities toward others who depend on him. Clearly, no such status attaches to other kinship relations like that of cousin or uncle in Western cultures, and it is hard to imagine a felicitous use of example (46):

(46) Please, I beg you, let the man go! \#He is an uncle.

The notion of status also explains why certain non-nominal predicates in the Personal Relationship frame allow omissions with existential rather than anaphoric interpretation. For instance, while friend can omit the FE Partner1 only under anaphoric interpretation, as shown in (47), the adjectives married and divorced denote social statuses and thus allow existential rather than anaphoric omission of this FE, as shown in (48) - (49):

(47) The mother strongly denies the claims, saying he is just a friend $[\varnothing$ Relative] who sometimes helps around the house.

(48) I get butterflies in my tummy just thinking of him. But the thing is he's married $\left[\varnothing^{\text {Relative }}\right]$, and he wants to see me on the side.

(49) In the suburbs, if a woman in her late twenties tells you her latest guy's got baggage, it means one thing, more often than not: He's divorced $[\varnothing$ Relative] with kids.

Apart from these status-based exceptions to (33), we have found no others thus far.

\section{Competing Explanations}

The frame-based implicational account of null-complement interpretation type can profitably be contrasted with alternative analyses. We argue in the following subsections that the frame-level generalization, as explained in (33), is preferable to single-factor 
explanations based, respectively, on lexical aspect and selectional restrictions. The framebased generalization captures the regularities that motivate such analyses-lexical units that share a frame also tend to share selectional restrictions and an Aktionsart classification - but (33) has the added benefit of avoiding the over- and undergeneralizations that result from attempts to tie the null-complementation affordance to a single semantic/pragmatic feature.

\subsection{Selectional Restrictions}

Resnik's $(1993,1996)$ theory of object omission is centered on the identity of the predicator. The intuition underlying the theory is that certain verbs carry enough information about their objects that they do not need to express them overtly; for example, direct objects of the verb eat are restricted to those denoting edible substances, while direct objects of the verb drink are restricted to those denoting potable liquids. With an eye toward natural-language-processing applications, Resnik formalizes the notion of selectional strength as an information-theoretic metric. Although selectional strength may seem to characterize only cases of INI, Resnik also applies the notion of selectional strength to DNI. The basic distinction between the two verb types is said to be that the verbs allowing INI are even stronger predictors of the direct-object head noun than those that allow DNI, and therefore do not require overt antecedents in the discourse for their objects.

Resnik's notion of selectional strength is not concerned with the specific semantics of predicates but rather with the processing of one aspect of a predicate's semantics: its selectional restrictions. However, if null-instantiation were really a by- 
product of processing, we would not expect to find that certain very strong selectors cannot license omission. Consider the example devein. This verb appears to license only one type of object: a NP with the head word shrimp. But there are no nonhabitual/generic uses in which the object can be omitted, contrary to what a selectional strength account would predict. On the other hand, devein behaves like other words relating to emptying containers and clearing areas of some substance or item. Some words in this class are shown in (50):

(50) bone.v, clear.v, core.v, debug.v, deforest.v, defrost.v, degrease.v, delouse.v, denude.v, descale.v, disembowel.v, divest.v, drain.v, empty.v, emptying.n, eviscerate.v, expurgate.v, gut.v, peel .v, purge.v, rid .v, scalp.v, skin.v, strip.v, unload.v, void.v

All the words in (50) belong to the Emptying frame, and, in non-generic sentences, they take an overt Source frame element as direct object, as in (51):

(51) Pat cleared the table of dishes.

Many of the verbs in the Emptying frame seem to be rather strong selectors. For example, bone occurs in the BNC primarily with overt objects that denote fishes or meats; core's overt objects are NPs headed by apple, lamb, or turkey. This kind of range does not seem to be significantly wider than that of, say, knit, or sew. Yet while knit and sew can omit their objects, bone and core cannot.

The selectional strength account not only faces exceptions related to omissibility but also makes incorrect predictions about the interpretations of many predicates that do allow omission. Consider, for instance, the verb know ('wissen/savoir'): it has extremely narrow selectional restrictions, taking only a proposition as a complement. Certainly, 
many different propositions are conceivable but the semantic type of the second argument is narrowly delimited and thus the interpretation type should, according to the Resnik model, be INI. But it is actually DNI. Similarly, verbs like deplane and board have very strong selectional preferences (for certain kinds of vehicles), but their interpretation is DNI rather than INI.

Resnik's account also fails to account for the uniformity of construal of a nullinstantiated FE across the LUs within a given frame, as captured by the generalization in (33). The interpretive procedure that Resnik has in mind depends on individual lexemes rather than on classes; thus, if LUs in the same frame have different selectional strengths, they should allow different null-instantiation interpretations for the same FE. As argued in section 3, although there are some exceptions to (33), there is generally no such variability within a frame.

An additional argument against a selectional-strength account is that one does not seem to find an association between argument omission and a lexeme's frequency or degree of polysemy. That is, there does not seem to be a cutoff point on one side of which verbs allow null instantiation and on the other side of which they do not (Ruppenhofer 2004). Furthermore, there is evidently no selectional-strength threshold above which verbs require definite null complements as against indefinite ones, or above which verbs that prohibit null instantiation allow it, as Resnik himself points out (1993:86).

Finally, although the selectional strength account is intended to apply to lexically licensed omissions only, it begs the question of what its relation to constructionally licensed omissions is. If constructional omissions are not sensitive to selectional strength, what is it that governs them? Conversely, when a verb that cannot lexically omit an 
argument (because it does not select a particular kind of filler strongly enough) does omit that argument in a particular constructional context (e.g., passive), Resnik's model provides no account of an interpreter's ability to construe such an utterance.

\subsection{The Aktionsart-based Account}

Rappaport Hovav and Levin (1998) (henceforth RH\&L) present a theory of argument realization based on the combination of verb meanings with a set of universal aspectual templates. This theory also makes predictions regarding null instantiations. According to RH\&L's theory, the idiosyncratic aspects of meaning (e.g., what distinguishes jog from run and trot) are recorded in the lexicon. Beside the lexicon there exists a fixed set of lexical semantic templates provided by Universal Grammar. These templates consist of various combinations of semantically primitive predicates. The templates correspond to a large degree to well known Aktionsart classes (e.g., activity and accomplishment). The event types that RH\&L recognize are listed in (52)-(56), along with their proposed decompositions:

(52) Activity: [x ACT <MANNER $>$ ]

(53) State: $[\mathrm{x}<\mathrm{STATE}>]$

(54) Achievement: [BECOME $[\mathrm{x}<\mathrm{STATE}>]]$

(55) Accomplishment (complex-causative): [[x ACT<MANNER $>$ ] CAUSE [BECOME $[\mathrm{y}<\mathrm{STATE}>]]]$

(56) Accomplishment: [x CAUSE [BECOME $[\mathrm{y}<\mathrm{STATE}>]]]$

Using a verb means combining the idiosyncratic lexical information with an event structure template, modeled as the insertion of a verbal 'constant' into the variable slot in 
the template (shown above in angled brackets). The slots are determined by type constraints; for instance, the Activity template shown in (52) has a slot that accepts a manner-denoting verbal constant. Based on its ontological type, each verbal constant is associated with one basic template in accordance with a so-called canonical realization rule. The number of participants that a constant specifies may exceed the number of slots in the template; for example, the activity verb sweep licenses two semantic roles (the agent and the surface), but the activity template, as shown in (52), licenses only one participant (the agent).

RH\&L propose to distinguish between those participant roles that are licensed by a template, called structure participants, and those licensed only by the verbal constant; the latter are called constant participants. According to RH\&L, the two kinds of participants are licensed in different ways. When a constant is inserted into a template other than the one specified for that constant by its canonical realization rule, the result is template augmentation, an affordance described as follows: "Event structure templates may be freely augmented up to other possible templates in the basic inventory of event structure templates" (111). An illustration of valence augmentation is found in example (57). Here, an activity verb (sweep) has been augmented up to the causativeaccomplishment type, depicted in example (55), resulting in the addition of a secondary predicate of result (clean) to the valence of sweep:

(57) She swept the floor clean.

Such permutations are strictly augmentative: no information contained in a verb's basic template can be discarded. This constraint is said to account for the failure of accomplishment verbs to receive an activity interpretation: the only available activity 
template is monovalent, so it cannot accommodate the argument array of an accomplishment verb. The impossibility of verb-valence reduction is used to explain the ill formedness of sentences like (58):

(58) *He built a house for six months.

RH\&L posit two well-formedness conditions on the syntactic realization of (basic or augmented) templates. These are listed in (59) - (60):

(59) Subevent Identification Condition: Each subevent in the event structure must be identified by a lexical head (e.g., a V, an A or a P) in the syntax.

(60) Argument Realization Condition: There must be an argument XP in the syntax for each structure participant in the event structure, and each argument XP in the syntax must be associated with an identified subevent in the event structure.

As discussed by RH\&L, two predictions regarding null instantiation arise from these constraints. First, all constant participants should in principle be omissible. This prediction applies to the objects of transitive activity verbs as well as the non-subject complements of bivalent stative verbs. The reason is that the activity and state templates, and the achievement template which contains a state template, have only one slotnamely, the slot for the active-voice subject. The objects of these verbs are thus only constant participants - that is, they are part of the conceptual semantics associated with the constants but do not have to be mapped into the syntax by the subevent-identification or the argument-realization conditions. RH\&L follow Brisson (1994) in assuming that constant participants are subject only to a recoverability condition based on 
prototypicality (115), which corresponds to what we call existential (or indefinite) interpretation.

Second, objects of resultative constructions need to be realized, because they are structure participants of the resultant-state predicate. This constraint applies not only to resultative predications in which an overt secondary predicate expresses the resultant state (e.g., [57] above), but also to lexical accomplishment verbs like break or dry: while the verb can identify both sub-events, the subject cannot discharge the realization requirement for the object. Thus, examples like (61) - (62) are (correctly) predicted to be ill formed:

(61) *She swept clean.

(62) She broke.

The predictions regarding null instantiation thus fall in line with RH\&L's observation that 'result verbs show a much narrower range of variation in meaning and syntactic context than manner verbs' (101). However, it is not clear if the account given is meant to extend to accomplishment verbs of creation like sew, paint, or write, which do not involve a change of state of an existing entity but instead denote an event of coming into existence. One could extend the account by choosing EXIST as the state predicate inside the accomplishment template. However, the template account would then make an incorrect prediction, because creation verbs can in fact omit their objects. As pointed out by Mittwoch (2005), creation verbs will null second arguments typically occur in the progressive and have activity readings, as in example (63):

(63) Kim was sewing in the bedroom. 
Apart from the analyses of specific predicates, one can identify two general problems arising from the RH\&L account. First, it does not extend to stative predicates with two obligatory arguments, e.g., resemble, like, and adjoin (see, e.g., [9] above). If the syntactic behavior of such predicates is meant to be captured by the simple state template, most of these predicates' null-instantiation properties are wrongly predicted. Recall that stative relational predicates like know omit their non-subject arguments only under an anaphoric interpretation (with the exception of the status-denoting subtype, e.g., married, retired). Second, RH\&L's account appears circular, insofar as it uses the realization facts — an argument is either a constant or a structure participant — to predict omissibility, even though omissibility seems to be the only factor that motivates the representational distinction in the first place. Neither RH\&L nor Wright and Levin (2000) mention any other linguistic symptom of the distinction. The alternative frame-based analysis preserves the insights of the aspectually based account in so far as aspectual class is typically shared by the verbs within a given frame. But it also accommodates data that the aspectual account does not. For instance, the verb prepare occurs with an anaphorically interpreted Activity FE in the Activity Prepare frame, exemplified in (64):

(64) I was excited about doing it again, and I prepared [ $\left.\varnothing^{\text {Activity }}\right]$ for a week in advance.

The fact that prepare denotes an activity would suggest, from an aspectual-class view, that the prepared-for-event FE should have an existential interpretation rather than an anaphoric interpretation. The reason is that, within the RH\&L account, the Activity template has only one structure participant, and constant participants are assumed to be 
recoverable as prototypes. However, the prediction is clearly not borne out for prepare in (64): the Activity has a clear discourse antecedent.

\section{Motivating the Frame-based Generalization}

The implicational regularity concerning the interpretation type of omissible arguments is descriptively robust. We have not explained, however, why there should be any connection at all between a predicate's frame semantics and the interpretation type of its omissible arguments. Nor have we explained why the interpretation type of a given lexically omissible FE is what it is - that is, we have not explained why, e.g., the Goal FE of arrive and enter in the Arriving frame is construed anaphorically when omitted, whereas the Produced Food FE of bake in the Cooking frame is construed existentially when omitted.

The answer we offer to the first question is an argument based on plausibility: there is other, independent evidence that frames are the sort of things that can influence argument construal. For instance, Sullivan (2007) has argued that detailed frame semantics determines which of various predicates with meanings in the same domain can participate in particular sub-mappings of a more general metaphor. For example, as she observes (5), the adjective brilliant, unlike the adjectives bright and sunny, never means 'cheerful' or 'happy,' as shown by the fact that one looks on the bright side rather than looking on the brilliant side. Sullivan notes that while non-metaphoric bright, sunny and dark often modify nouns denoting a location (bright room, sunny place, and dark corner), brilliant is rarely used in this way: brilliant place and brilliant street are uncommon. Sullivan attributes this difference to the fact that adjectives like bright and sunny usually 
evoke the Location of Light frame, which involves a location where the light is apparent, whereas brilliant typically refers to light emanating from a source, as in brilliant star or brilliant torch. These uses evoke the Light Movement frame, which does not contain a location FE. Accordingly, adjectives like brilliant cannot participate in the mapping HAPPY STATES ARE LIT LOCATIONS, apparent in preposition phrases like in a dark state of mind, which is part of the larger HAPPINESS IS LIGHT metaphor.

In Sullivan's metaphor analysis, the connection between a predicate's frame semantics and the construal of its arguments involves conceptual structure. In the case of null instantiation, to which we now return, the connection appears to come from discourse-pragmatic constraints on frames. Specifically, we suggest that particular FEs in particular frames may have strong biases towards certain discourse statuses. Michaelis and Francis (2007) observe the influence of this bias on quantifier scoping in their discussion of the data in (65) - (66):

(65) *An acorn grew into every oak.

(66) An oak grew out of every acorn.

Michaelis and Francis attribute the acceptability contrast in (65) - (66) to a discoursepragmatic contrast between the two lexical classes: 'transformation' verbs, exemplified in (65), require a topical subject, expressing the initial state of the entity; 'creation' verbs, exemplified in (66), allow a focal subject, expressing the final state of the entity. Their evidence for a discourse-pragmatic contrast between the two verb classes comes from constraints on pronominal expression: the 'final state' (oblique) argument of the transformation class cannot be pronominal, indicating that it is focal (and, by inference, that the 'initial state' argument is topical): 
*An ACORN grew into it.

By contrast, the 'initial state' (oblique) argument of the creation class is readily expressed by a pronominal argument, indicating that this argument is topical, while the 'final state' argument (expressed by the subject NP) is focal:

(68) An OAK grew out of it.

Because topical NPs normally outrank non-topical NPs and subjects outrank objects with regard to scope (Ioup 1975), a clash results in (65). This clash involves the interaction of world knowledge with a verb-class-based topicality constraint: the 'initial state' argument of a transformation verb must be interpreted as topical. It is thereby also interpreted as specific, in accordance with Lambrecht's topic acceptability scale (Lambrecht 1994:165171). Because the NP an acorn receives a specific interpretation, its quantifier cannot be interpreted as taking narrow scope relative to the universal quantifier in into every oak. But if the subject an acorn is given wide scope, as required by the transformation class, an anomalous reading is forced: a single oak acorn cannot produce multiple oaks. The grammaticality contrast described here provides support for the contention that verb classes can constrain the discourse-pragmatic properties of their arguments. Note that it would be insufficient to describe the contrast in (65) - (66) by saying 'the verb grow requires its theme argument to be topical', because the theme argument of the 'create' pattern in (66) exhibits no such constraint. Instead, the topicality constraint attaches to a particular argument of a particular verb class: the 'initial state' argument of the transformation class. ${ }^{5}$

\footnotetext{
${ }^{5}$ Admittedly, FrameNet itself does not systematically distinguish between the 'creation' and 'transformation' lexical classes. The verbal LU create and the verbal LU transform do belong to different frames (create to Intentionally Create and transform to Cause Change), with correspondingly distinct FEs (e.g., the 'initial state' argument of transform is labeled Initial Category while that of create is labeled
} 
Additional evidence that frames impose particular discourse statuses on particular FEs comes from the fact that the interpretation of an omissible argument strongly tends to match both the dominant interpretation of overtly instantiated instances of that FE and the dominant interpretation of overt and non-overt instances considered together. This tendency is illustrated by the analysis summarized in Table 2. In this analysis, which, like that reported in section 3.1, was based on BNC data, we examined the argumentexpression patterns of 19 randomly selected verbal LUs licensing null complements (two such verbs, contribute and donate, appear twice, as each allows two distinct unexpressed FEs). The organization of this table is as follows: the first column shows the 19 verbal LUs sampled (as well as the FE in question, if this is not obvious); the second column shows the predominant null-complement construal for that verb (e.g., DNI in the case of arrive); the third column indicates the total tokens of this verb examined; the fourth column indicates the percentage of tokens in which the relevant FE is null instantiated; the fifth column indicates the percentage of tokens of each verb in which the target FE, whether expressed or unexpressed, matched the dominant definiteness value for that FE (e.g., either DNI or pronominal/definite morphosyntactic encoding of the goal argument in the case of arrive); finally, the sixth column indicates the number of instances in which an overt instantiation of the FE matched the dominant definiteness value of that FE when covert. Table 2 shows that, for instance, in the case of arrive, the interpretation for an unexpressed Goal FE is definite, and that of all overt instantiations of this FE occurring with arrive, 94.6\% are definite, e.g., in Swaziland, in the clubhouse. Table 2 shows that, with the exception of the LUs reap and carve, the interpretation of the null instantiated 
uses agrees with the majority of all the uses — null instantiated and overt combined.

Further, if one considers only overt arguments for each predicator, the predominant interpretation of the relevant argument when overt matches the construal type of that argument when omitted. For instance, among all uses of pass, in the sense of 'receive a passing grade on,' $59.1 \%$ of the overt objects have a definite interpretation and $22.7 \%$ of the overt objects have an indefinite interpretation. 


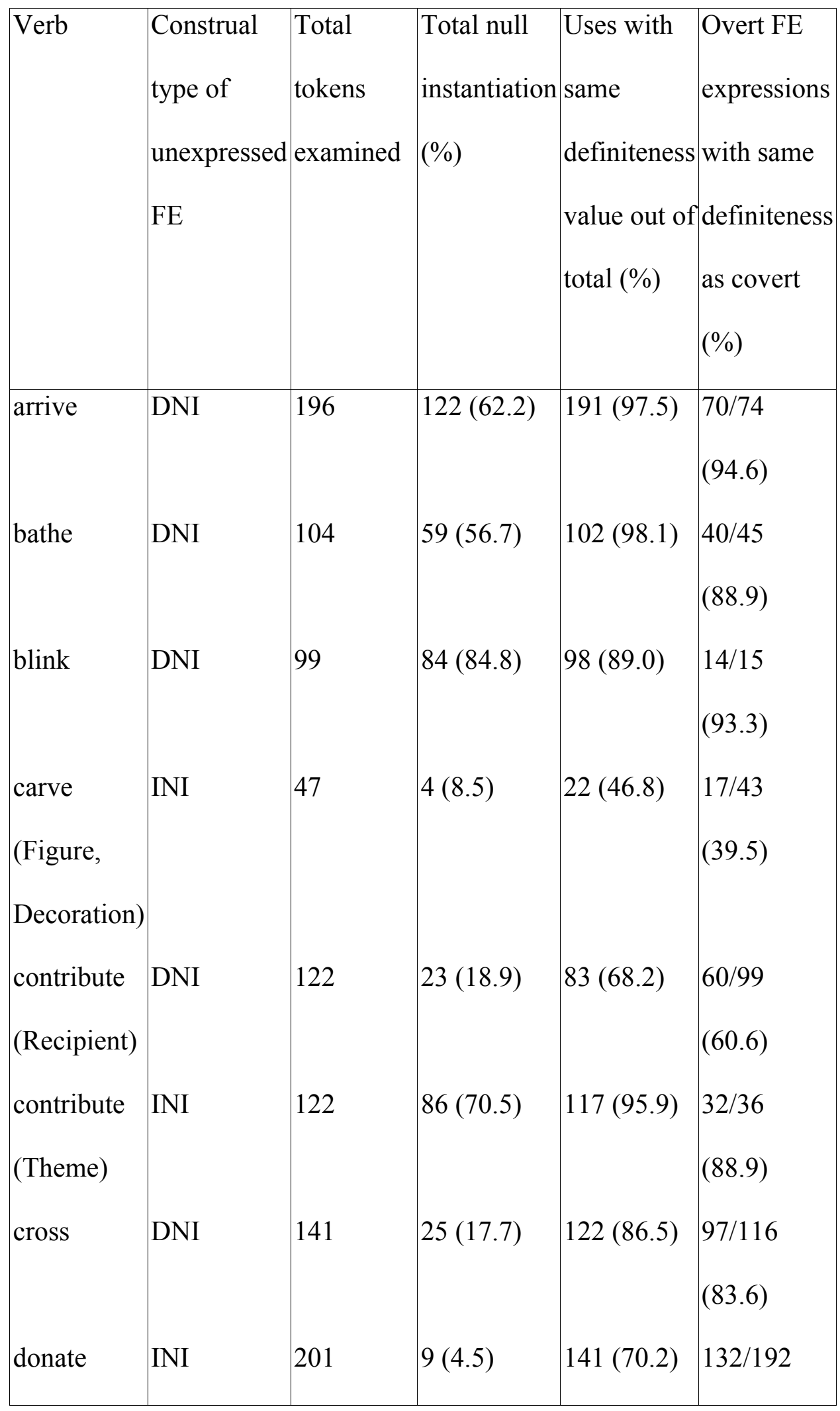




\begin{tabular}{|c|c|c|c|c|c|}
\hline (Theme) & & & & & (68.7) \\
\hline donate & DNI & 159 & 77 (48.4) & $143(89.9)$ & $66 / 82$ \\
\hline (Recipient) & & & & & $(80.5)$ \\
\hline dress & DNI & 78 & $62(79.5)$ & 77 (98.7) & $15 / 16$ \\
\hline & & & & & (93.4) \\
\hline eat & INI & 125 & 96 (76.8) & $111(88.8)$ & $15 / 29$ \\
\hline & & & & & (51.7) \\
\hline enter & DNI & 80 & $16(20.0)$ & 75 (93.7) & $59 / 64$ \\
\hline & & & & & (92.1) \\
\hline govern & DNI & 60 & $20(33.3)$ & $53(88.5)$ & $33 / 40$ \\
\hline & & & & & $(82.5)$ \\
\hline grab & DNI & 137 & $4(2.9)$ & 118 (86.1) & $\begin{array}{l}124 / 133 \\
(93.2)\end{array}$ \\
\hline obey & DNI & 188 & $43(22.9)$ & 143 (76.1) & $\begin{array}{l}100 / 145 \\
(69.0)\end{array}$ \\
\hline $\begin{array}{l}\text { pass } \\
\text { (Exam) }\end{array}$ & DNI & 22 & $4(18.2)$ & $17(77.3)$ & $\begin{array}{l}13 / 18 \\
(72.2)\end{array}$ \\
\hline $\begin{array}{l}\text { pass } \\
\text { (Landmark) }\end{array}$ & DNI & 56 & $14(25.0)$ & 43 (76.7) & $\begin{array}{l}29 / 42 \\
(69.0)\end{array}$ \\
\hline reap & INI & 51 & $15(29.4)$ & $25(49.0)$ & $\begin{array}{l}16 / 36 \\
(44.4)\end{array}$ \\
\hline shrug & DNI & 112 & $100(89.3)$ & $112(100.0)$ & $\begin{array}{l}12 / 12 \\
(100.0)\end{array}$ \\
\hline
\end{tabular}




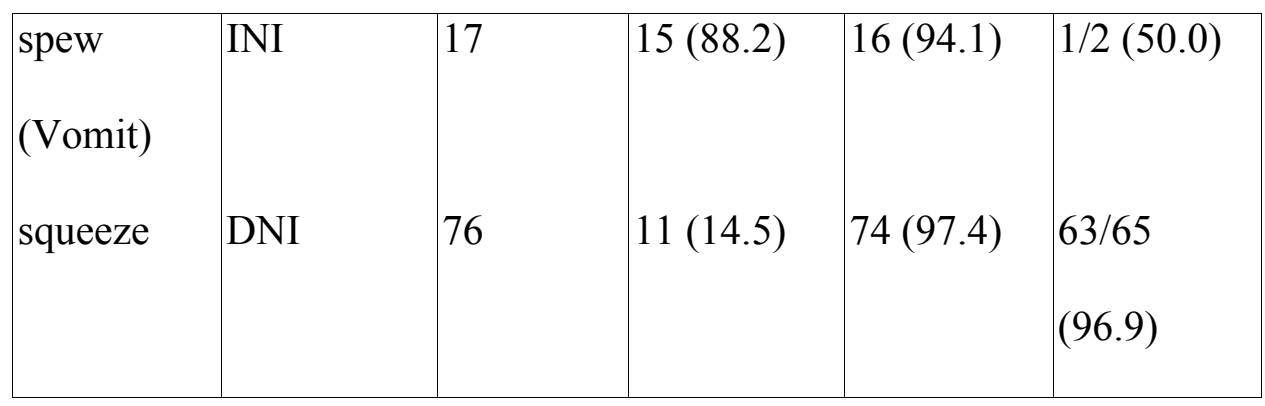

Table 2: Null complement type and overall definiteness for select lexical units

The data reported in Table 2 suggest that an argument's discourse-pragmatic status is determined at the lexeme level, perhaps as a constraint on the lexeme's valence members. This finding lends further support to Lambrecht's (1995) observation that informationpackaging goals (the need to foreground or background a particular argument) drive lexeme selection. Because lexemes have idiosyncratic properties, we expect to find verbs whose overt definiteness preferences do not match their covert construal patterns. As mentioned, the verb carve, belonging to the Create Representation frame, is one such exception. But what of frame-level patterns? In a current research effort, the two authors of this article are attempting to determine whether the observed correlation between null-complement interpretation type and overt-complement definiteness holds as well at the frame level. Certain facts about constructionally licensed null complementation suggest that this correlation may indeed prove to be a general one. Note the following examples, discussed by Ruppenhofer (2004) and Ruppenhofer and Michaelis (2010):

(69) Blend all the ingredients in an electric blender. Serve [the dish] cold.

(70) [This product] contains alcohol.

(71) $[\mathrm{I}]$ watched dog herding sheep. 
In all these constructions, the omitted argument is interpreted anaphorically or deictically, and overt realizations of those arguments also must be, or predominantly are, definite. For instance, the dish to be prepared in a recipe context is highly accessible as the discourse topic in (69), as are the product bearing a particular label in (70) and the omitted subjects in diaries in (71). Overt expressions of these referents are morphologically definite; for example, as shown, the best reconstruction of the subject of example (70) is the definite NP this product.

Admittedly, the evidence is not so clear-cut for other constructions. In the case of the passive construction, omitted agents and causes receive an indefinite interpretation. The majority of overtly expressed by-phrases also tend to be indefinite, but the margin seems to be a fairly slim one. In a random sample of 100 passive predications containing overt by-phrase agents or causes taken from the $\mathrm{BNC}$, we found that 54 were indefinite and 46 definite. In a parallel random sample of only get-passives, also taken from the BNC, the margin was reduced to 51 indefinite agents or causes versus 49 definite ones. $^{6}$ Because for both samples the standard error for the sample percentage is about $5 \%$, it may actually be the case that definite agents and causes constitute the majority of byphrase agents and causes in the BNC. The overt instances of passives thus do not show a clear preference for a definite or indefinite agent or cause.

\footnotetext{
${ }^{6}$ We produced both samples by retrieving all past participle tokens, identified via the PennTreeBank part-of-speech tag VVN, followed by the preposition by within five words. In the case of the getpassives, the participle also had to immediately follow a form of get. The candidates were randomized and then inspected manually to eliminate accidental matches like had sat by the river or got defeated by a large margin.
} 


\section{Narrow Scope Generalizations}

The predictive generalization that we have offered in this paper is of limited scope, in two respects. First, it predicts only the construal type of an argument once omitted, and not which arguments are omissible or what predicators license omissible arguments. Second, it applies only when two conditions are met: the predicator belongs to a specific frame, and it licenses the omission of a particular frame element.

It would of course be useful to predict which predicators allow null-instantiation of any of their arguments, and/or which kinds of arguments are omissible, as these broader generalizations would apply to larger sets of elements — all predicators, or all arguments with certain characteristics. However, no reliable large-scale generalizations have thus far been found.

The selectional preference strength and the Aktionsart-based accounts that we discussed above seek large-scale generalization of this nature. Both make predictions about which types of arguments are omissible, and thereby, also implicit predictions about which predicates license null complements. But recall that, as we showed above, while these accounts handle certain facts very nicely - the Aktionsart account, for example, captures the fact that objects in the resultative construction are generally not omissible - they also make many incorrect predictions. For instance, the selectional preference strength account incorrectly predicts that a null complement of know will be construed indefinitely rather than definitely, based on the predicate's narrow selectional preference for propositions.

As discussed by Ruppenhofer (2004:Chapter 4), there are other potential bases for predicting which kinds of arguments are omissible. For instance, the thematic role of an 
argument - in the sense of the small set of universal semantic roles posited by Gruber (1965) and Fillmore (1968) — appears to be a key source of generalizations about null instantiation that would cut across both lexeme classes and frames. Curiously, semanticrole based generalizations have not been discussed in the literature on null complementation. Fillmore (1986) notes only that Patients (or Themes) do not seem readily omissible. From the examples he discusses it is clear, however, that thematic roles do not allow generalizations about null instantiation. As shown by the following contrast sets involving instances of the classic thematic-role types Source (72), Experiencer (73) and Recipient (74), respectively, we cannot predict for all instances of these roles either omissibility or the interpretation type under omission:

(72) Source

a. Sue arrived in Rome [ $\left.\varnothing^{\text {Source }}\right]$. (existential)

b. Sue left $\left[\varnothing^{\text {Source }}\right]$. (anaphoric)

c. Oil exuded *(from Myrna's hands $\left.{ }^{\text {Source }}\right)$.

\section{(73) Experiencer}

a. This building is famously confusing [ $\left.\varnothing^{\text {Experiencer }}\right]$. (existential)

b. Recently - by this i mean around a month or so, my ears started hurting $\left[\varnothing^{\text {Experiencer }}\right]$ a lot. (anaphoric)

c. He strikes * (me experiencer $)$ as a rather shy private fellow.

(74) Recipient

a. That guy's distributing free movie tickets [ $\left.\varnothing^{\text {Recipient }}\right]$. (existential) 


\section{b. I donated $\$ 20\left[\varnothing^{\text {Recipient }}\right]$. (anaphoric) \\ c. I handed $\$ 20 *$ (to her $\left.{ }^{\text {Recipient }}\right)$.}

The morphosyntax of the argument might also appear to be a profitable place to look for generalizations about argument omission. That is, it might be the case that phrases of a certain type are always omissible. A few examples will suffice to show, however, that phrase type does not predict omissibility. The examples in (75) show, for instance, that some object NPs are omissible, while others are not, and that those objects that are omissible do not all share the same interpretation type: while the object of knit in (75a) is omitted under an INI construal, that of win in (75b) is omitted under a DNI construal. Example (76) provides parallel evidence for that-complement clauses.

(75) Object NPs

a. Sue's knitting [something]. (existential)

b. I won [the game]. (anaphoric)

c. I found *[the ring].

That-complement clauses

a. I've had such a hard life, but still I hope. (existential)

b. I know [that he said that]. (anaphoric)

c. He blurted out *[that he wanted to take Stein out that evening].

Other possible generalizations about complement omissibility that are explored in Ruppenhofer (2004) involve the lemma frequency of predicators, their degree of polysemy, the definiteness profiles of arguments (as described in section 5 above), verb 
neutrality and the taxonomic level of the complement's referent. None of these were found to predict complement omissibility.

These failures need not be discouraging, however, insofar as we are dealing with an aspect of argument realization licensed by lexemes, which may differ from one another in idiosyncratic ways. Such idiosyncratic differences are revealed by synonymdifferentiation exercises involving pairs like mislead and deceive and accomplish and achieve. The lexicon is designed to provide alternative argument-encoding options for a given event-structure representation, as in the contrast between the verbs transform and create, on the one hand, and replace and substitute, on the other. It is thus not surprising that argument-omission generalizations should also be tied to lexical entries and their frame-based subgroupings.

\section{Conclusion}

In this chapter we have argued that, faced with the idiosyncrasies of nullcomplementation phenomena, one should look for narrow-scope generalizations to gain predictive power. Our specific contribution was to propose an implicational regularity that predicts a uniform interpretation type for a given FE across all LUs of the frame that allow that FE's omission. We have argued that our frame-based analysis has better coverage and accuracy than explanations targeting general linguistic features like Aktionsart or selectional strength, which correlate with argument omission for some lexical classes. In addition, we have provided a preliminary rationale for the uniformity of interpretation of a given unexpressed FE, by observing a correlation between the dominant definiteness value of overt instances of a given FE and the interpretation type 
of covert instances of that same FE. Finally, we have argued that null-complementation phenomena do not lend themselves to more general predictions than the one we have provided. In particular, we have argued that neither the construal of a complement when unrealized nor the null-complementation affordance itself can be predicted from general properties like aspectual-class membership or semantic-role type. One moral of this story is that predictive principles must allow for lexical idiosyncrasy even while acknowledging semantic regularities like frame-based organization.

Another moral concerns the contention that "much of the conceptual material bundled up inside a lexical item is invisible to syntax" (Jackendoff 1997:34). In contrast to semantic roles, frame-specific participant roles have been viewed as yielding no significant syntactic generalizations. For example, Jackendoff says that "the syntactic reflexes of lexical meaning differences are relatively coarse" (34). The phenomena reported in this paper suggest that in fact one significant part of sentence interpretation, the construal of an omitted argument, is dependent on a fine-grained level of lexical organization: frame-semantic meaning.

\section{References}

Brisson, Christine. 1994. "The Licensing of Unexpressed Objects in English Verbs." CLS 30: 90-102.

Fillmore, Charles J. 1968. “The Case for Case.” In Universals in Linguistic Theory, ed. by Emmon Bach and Robert Harms, 1-88. New York: Holt, Rinehart and Winston. 
Fillmore, Charles J. 1982. "Frame Semantics.” In Linguistics in the Morning Calm, ed. by the Linguistic Society of Korea, 111-138. Hanshin, Seoul.

Fillmore, Charles J. 1985. "Frames and the Semantics of Understanding." Quaderni di Semantica 6: 222-254.

Fillmore, Charles J. 1986. "Pragmatically Controlled Zero Anaphora." BLS 12: 95-107.

Gillon, Brendan. 2012. "Implicit Complements: A Dilemma for Model-Theoretic Semantics." Linguistics and Philosophy 35: 313-359.

Goldberg, Adele. 2005. "Constructions, Lexical Semantics and the Correspondence Principle: Accounting for Generalizations and Subregularities in the Realization of Arguments." In The Syntax of Aspect, ed. by Nomi Erteschik-Shir and Tova Rapoport, 212-236. Oxford: Oxford University Press.

Goldberg, Adele. 2006. Constructions at Work. Oxford: Oxford University Press.

Goldberg, Adele and Farrell Ackerman. 2001. "The Pragmatics of Obligatory Adjuncts." Language 77: 798-814

Gruber, Jeffrey. 1965. Studies in Lexical Relations. Cambridge, MA: M.I.T dissertation.

Gundel, Jeanette K., Nancy Hedberg, and Ron Zacharski. 1993. "Referring Expressions in Discourse." Language 69: 274-307.

Ioup, Georgette. 1975. “Some Universals of Quantifier Scope.” In Syntax and Semantics, vol. 4, ed. by John Kimball, 37-58. New York: Academic Press.

Jackendoff, Ray. 1997. The Architecture of the Language Faculty. Cambridge, MA: MIT Press.

Lambrecht, Knud. 1994. Information Structure and Sentence Form. Cambridge: Cambridge University Press. 
Lambrecht, Knud. 1995. “The Pragmatics of Case.” In Essays in Semantics and Pragmatics, ed. by Masayoshi Shibatani and Sandra A. Thompson, 145-190. Amsterdam: John Benjamins.

Lambrecht, Knud and Kevin Lemoine. 2005. "Definite Null Objects in (Spoken) French: A Construction Grammar Account." In Grammatical Constructions: Back to the Roots, ed. by Hans C. Boas and Mirjam Fried, 157-199. Amsterdam: John Benjamins.

Michaelis, Laura A., and Hartwell S. Francis. 2007. "Lexical Subjects and the Conflation Strategy." In Topics in the Grammar-Pragmatics Interface: Papers in Honor of Jeanette K. Gundel, ed. by Nancy Hedberg and Ronald Zacharski, 19-48. Amsterdam: John Benjamins.

Mittwoch, Anita. 2005. "Unspecified Arguments in Episodic and Habitual Sentences." In The Syntax of Aspect, ed. by Nomi Erteschik-Shir and Tova Rapoport, 237-254. Oxford: Oxford University Press.

Rappaport Hovav, Malka, and Beth Levin. 1998. "Building Verb Meanings". In The Projection of Arguments: Lexical and Compositional Factors, ed. by Miriam Butt and Wilhelm Geuder, 97-134. Stanford: CSLI.

Resnik, Philip. 1993. Selection and Information: A Class-based Approach to Lexical Relationships. Philadelphia: University of Pennsylvania dissertation.

Resnik, Philip. 1996. "Selectional Constraints: An Information-theoretic Model and its Computational Realization." Cognition 61: 127-59.

Ruppenhofer, Josef, 2004. The Interaction of Valence and Information Structure. Berkeley: University of California dissertation. 
Ruppenhofer, Josef, Michael Ellsworth, Miriam R. L. Petruck, Christopher R. Johnson, and Jan Scheffczyk. 2006. FrameNet II: Extended Theory and Practice. Berkeley, CA: ICSI. http://framenet.icsi.berkeley.edu/book/book.html.

Ruppenhofer, Josef and Laura A. Michaelis. 2010. "A Constructional Account of Genrebased Argument Omissions." Constructions and Frames 2: 158-184.

Wright, Saundra, and Beth Levin. 2000. "Unspecified Object Contexts with Activity and Change of State Verbs.'Paper presented at the LSA Annual Meeting, Chicago, IL 